\title{
The Relationship between Bulk Property and Property Distribution in Thin-Wall Injection Molded PP at Different Molecular Weight and Molecular Weight Distribution
}

\author{
Keisuke Maeda ${ }^{1}$, Koji Yamada ${ }^{2}$, Kazushi Yamada ${ }^{*}$, Masaya Kotaki ${ }^{3,4}$, Hiroyuki Nishimura1 \\ ${ }^{1}$ Department of Advanced Fibro Science, Kyoto Institute of Technology, Kyoto, Japan \\ ${ }^{2}$ Osaka Municipal Technical Research Institute, Osaka, Japan \\ ${ }^{3}$ Center for Fiber and Textile Science, Kyoto Institute of Technology, Kyoto, Japan \\ ${ }^{4}$ Kaneka US Material Research Center, Kaneka Americas Holding, Inc., TX, USA \\ Email: "kazushi@kit.ac.jp
}

Received 11 December 2015; accepted 16 January 2016; published 19 January 2016

Copyright @ 2016 by authors and Scientific Research Publishing Inc.

This work is licensed under the Creative Commons Attribution International License (CC BY).

http://creativecommons.org/licenses/by/4.0/

(c) ()

\section{Abstract}

Thin-wall injection molded parts have been paid much attention to the lightweight saving from viewpoints of natural resources saving. In the injection molding, skin-core structure can be found in the parts. This skin-core structure affects the property of completed injection molding parts (bulk property) even if in thin-wall injection molding. However, there is a few research about the relationship between bulk property and internal property distribution in the injection molding specimen. In this study, thin-wall injection molded parts of polypropylene (PP) were prepared by 4 different molecular weight and molecular weight distribution to reveal the relationship between bulk property and property distribution. These characteristics were investigated by using tensile test, fracture toughness characterized by Essential Work of Fracture (EWF) method for bulk property and film tensile test by sliced sample for tensile property distribution. The property distribution test results revealed that the highly bulk property sample had thicker highly mechanical property layer on its surface.

\section{Keywords}

Molecular Weight, Molecular Weight Distribution, Fracture Toughness, Property Distribution, Thin-Wall, Injection Molding

\footnotetext{
${ }^{*}$ Corresponding author.
}

How to cite this paper: Maeda, K., Yamada, K., Yamada, K., Kotaki, M. and Nishimura, H. (2016) The Relationship between Bulk Property and Property Distribution in Thin-Wall Injection Molded PP at Different Molecular Weight and Molecular Weight Distribution. Advances in Materials Physics and Chemistry, 6, 1-8. http://dx.doi.org/10.4236/ampc.2016.61001 


\section{Introduction}

Injection molding is one of the most popular methods to make plastic products. The parts made by this technique were used in various situations such as transportation equipment, electric appliance, and supplies. Recently, light-weighting is very important theme because their weight-saving causes low emission of carbon dioxide, convenience and economy. The one of the simple ways to light-weighting is thin-wall injection molding. However, the resin was rapidly cooled by mold, so that the skin and core layer of molding article formed different structure and this structure influenced bulk property strongly [1]-[4]. This heterogeneous structure which is called skin-core structure is formed even if it is a thin-wall. It was known that the percentage of this skin layer thickness to the injection molded specimen thickness increased as decreased the specimen thickness [5]. So it is very important to understand the relationship between bulk mechanical property and mechanical property distribution by the difference of heterogeneous skin-core structure. In recent researches, effect of $\beta$ phase crystalline nucleating agent added polypropylene (PP) [6] and influence of ultra-high speed injection molding [7] were studied to reveal the relationship between non-uniform structure and property of thin-wall injection molding products. Moreover, this non-uniform structure-property relationship was also investigated in composite material [8] and non-olefin resin based materials [9]. Nevertheless, molecular weight and molecular weight distribution effects on structure-property relationship of thick-wall materials were well studied [10]-[12]. Comparably, it has not been reported in the case of thin-wall injection molding products. Besides, there were a number of reports about injection molding products in various conditions, but almost reports focused on only internal structure or property. Especially in property measurement, most researchers focused on the properties of entire crosssection in injection molding product. However, property distribution which has the strong relationship with skincore structure has not been hardly studied except hardness and scratch resistance property of surface [13]-[17]. In this research, the relationship between bulk mechanical property and mechanical property distribution of thin-wall injection molded polypropylene with different molecular weight and molecular weight distribution was investigated. The bulk mechanical properties were characterized in terms of static tensile property and fracture toughness by using essential work of fracture method [18]. The mechanical property distribution was measured by tensile test with thin-sliced dumbbell film obtained from bulk specimen.

\section{Experimental}

\subsection{Material \& Injection Molding Conditions}

In this study, 4 different kinds of homo-PP resins were used. The molecular characteristics were summarized in Table 1. These resins had different molecular weight and distribution [12]. In Table 1, there are 4 types of PP resins were expressed by using two characters. $\mathrm{H}$ and $\mathrm{L}$ describe higher and lower molecular weight respectively. $\mathrm{N}, \mathrm{M}$ and $\mathrm{W}$ describe narrow, middle and wide molecular weight distribution respectively. Thin-wall specimen was prepared by injection molding. Resin temperature and mold temperature were controlled $240^{\circ} \mathrm{C}$ and $40^{\circ} \mathrm{C}$. Packing pressure, holding pressure and cooling time were 50, $30 \mathrm{MPa}$ and 20 seconds. Injection speed was controlled at $100 \mathrm{~mm} / \mathrm{s}$.

\subsection{Tensile Test}

To measure the static tensile property behavior, tensile properties were measured using anuniversal testing machine (Instron Corp., Type; 55R4206). The $1 \mathrm{~mm}$ thick dumbbell specimen (JIS K-7162-1BA) was used and the longitudinal direction was set along the FD direction. Tensile tests were performed under room temperature (RT) condition at a crosshead speed of $10 \mathrm{~mm} / \mathrm{min}$.

Table 1. The molecular characteristics of PP resins.

\begin{tabular}{cccc}
\hline & $M_{w}\left(\times 10^{4}\right)$ & $M_{n}\left(\times 10^{4}\right)$ & MWD $\left(M_{w} / M_{n}\right)(-)$ \\
\hline LN & 19.0 & 6.4 & 3.0 \\
LM & 19.0 & 3.5 & 5.4 \\
HM & 40.0 & 7.4 & 5.4 \\
HW & 41.0 & 4.2 & 9.8 \\
\hline
\end{tabular}




\subsection{Essential Work of Fracture Method}

Fracture toughness of thin-wall specimens was evaluated by EWF tests using the universal testing machine with double edge notched specimens (see Figure 1). The dimension of the test piece was $100 \times 20 \times 1 \mathrm{~mm}$ and longitudinal direction was set along the FD direction. U-shaped notch with $2 \mathrm{~mm}$ width was introduced followed by a $1 \mathrm{~mm}$ initial crack at the tip of the U-notch. A ligament length was varied by the depth of U-notch as 3, 4, 5, 6, and $7 \mathrm{~mm}$. The test was performed under RT condition at a crosshead speed of $10 \mathrm{~mm} / \mathrm{min}$. In EWF method, the energy for destruction of specimen $W_{f}$ is divided into the energy of deformation in plastic zone $W_{e}$ and crack propagation in the process zone $W_{p}$ (See Equation (1)). Equation (2) was given by each fracture energy per unit area from Equation (1) and the energy for destruction of specimen per unit area $w_{f}$ was given to divide the Equation (2) by the area of ligament part. In Equation (3), $w_{e}$ is the essential fracture toughness of the specimen.

$$
\begin{gathered}
W_{f}=W_{e}+W_{p} \\
W_{f}=w_{e} l t+\varphi w_{p} l^{2} t \\
w_{f}=W_{f} / l t=w_{e}+\varphi w_{p} l
\end{gathered}
$$

where, $l$ is ligament length, $t$ is the thickness of the specimen, and $\varphi$ is shape factor of plastic zone.

\subsection{Tensile Test}

To measure the difference of mechanical property distribution, tensile property distribution was measured using universal testing machine. The samples were sliced into every $50 \mu \mathrm{m}$ thick films from the sample surface to 500 $\mu \mathrm{m}$ in depth with a rotary microtome (Leica Biosystems Ltd., RM2235) at room temperature. After this thinsliced process, dumbbell specimen (JIS K-6251-7) for tensile property distribution was stamped out. The selected sample layers were 0 - 50, 50 - 100, 100 - 150, 150 - 200, 200 - 250 and 450 - $500 \mu \mathrm{m}$ depth from the surface on each sample.

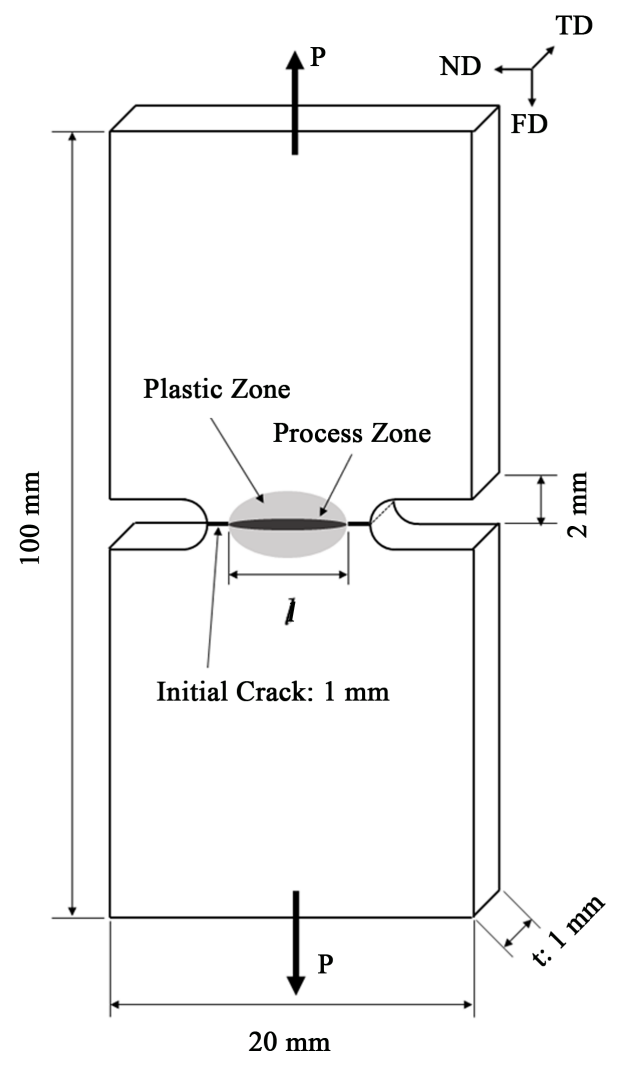

Figure 1. Schematic drawing of DENT specimen for EWF test. 


\section{Results and Discussion}

\subsection{Static Tensile Property}

Figure 2 shows the stress-strain curves of the 4 different samples from tensile test. Figure 2(a) is the full stressstrain curve and Figure 2(b) is elongated stress-strain curve around yield point. Low molecular weight samples (LN and LM) did not break in this test. On the other hand, high molecular weight samples (HM and HW) were broken and HM showed lower strain at break than HW. In Figure 2(b), there is quick drop between the strains of $15 \%-20 \%$ in LN LM, and HW. According to the decreasing the molecular weight and increasing molecular weight distribution, this quick drop value increase. It is known that the decreasing molecular weight affects the clarification of necking behavior [19], this quick drop caused by necking. Table 2 shows the results of tensile test. HM showed higher modulus and yield stress than LM so high molecular weight affects the increasing modulus and yield stress. As compared with LN and LM, LN showed higher modulus and yield stress than LM. This behavior was also measured in comparison of $\mathrm{HM}$ with $\mathrm{HW}$, hence it is considered that the narrower molecular weight distribution affects the increasing of the modulus and yield stress because narrower molecular weight distribution sample has highly molecular orientation toward to FD direction near the surface than broad molecular weight distribution sample [12].

\subsection{Fracture Toughness}

Figure 3 shows the results of fracture toughness obtained by EWF tests. The fracture toughness we of LN, LM, $\mathrm{HM}$ and HW were 21.5, 14.8, 23.5 and $18.3 \mathrm{~kJ} / \mathrm{mm}^{2}$, respectively. In LM and HM, HM showed higher fracture toughness than LM. It was indicated that the high molecular weight affected the high fracture toughness. In LN and LM, the narrow molecular weight distribution sample showed higher fracture toughness as compared with the wider that. In the case of HM and HW, the fracture toughness indicated the same tendency with LN and LM. From these results, it was found that the higher molecular weight and the narrower molecular weight distribution affect the increasing of the fracture toughness.

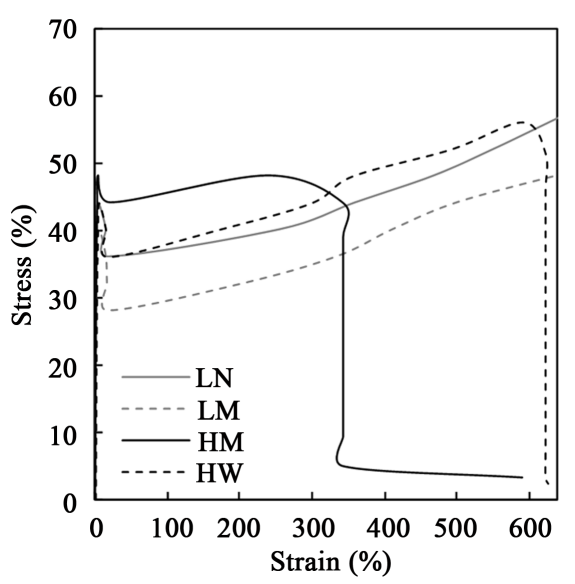

(a)

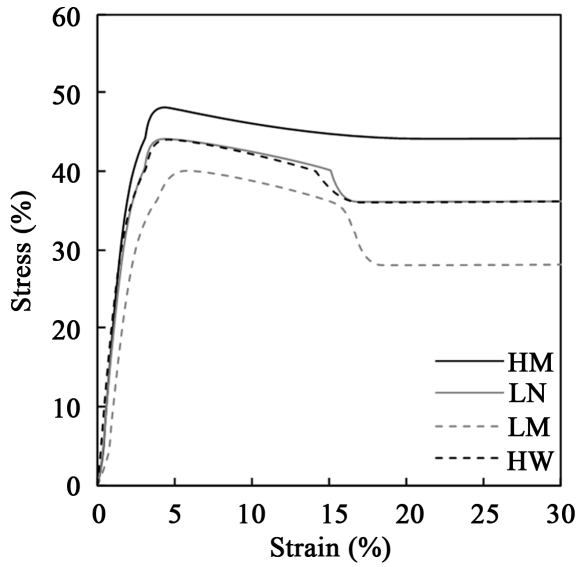

(b)

Figure 2. The bulk stress-strain curves of the samples: (a) Full stress-strain curve; (b) Enlarged stress-strain curve of initial part.

Table 2. The results of bulk mechanical properties from tensile test [14].

\begin{tabular}{cccc}
\hline & Modulus (GPa) & Yield Stress (MPa) & Stress at Break (MPa) \\
\hline LN & $2.4 \pm 0.2$ & $44 \pm 0.0$ & - \\
LM & $1.9 \pm 0.1$ & $40 \pm 0.0$ & - \\
HM & $2.5 \pm 0.2$ & $48 \pm 0.0$ & $43.2 \pm 1.1$ \\
HW & $2.2 \pm 0.1$ & $44 \pm 0.1$ & $52.7 \pm 3.1$ \\
\hline
\end{tabular}




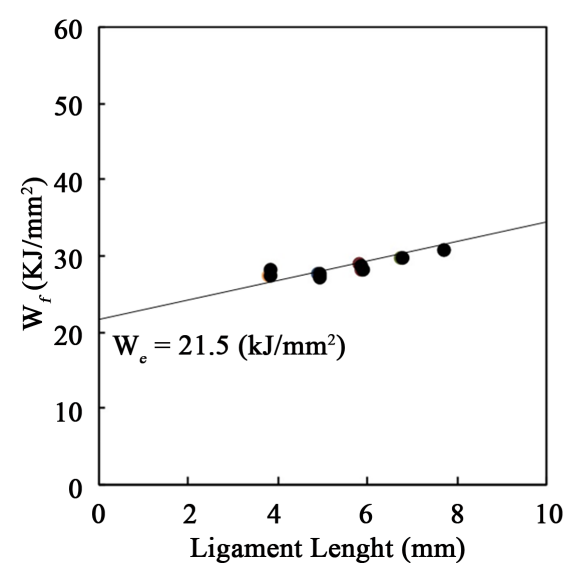

(a)

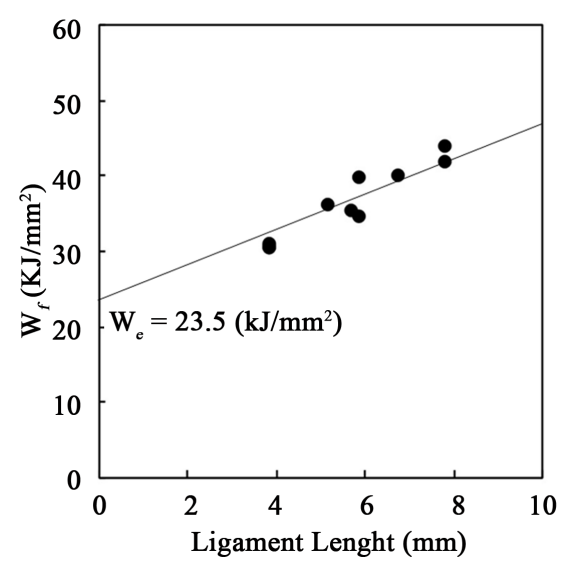

(c)

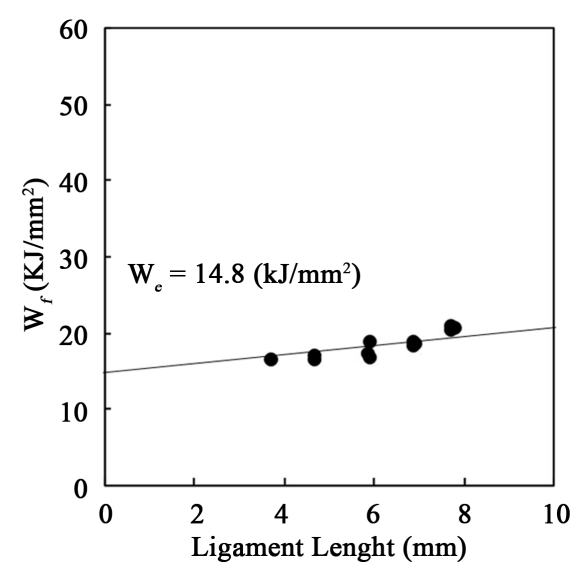

(b)

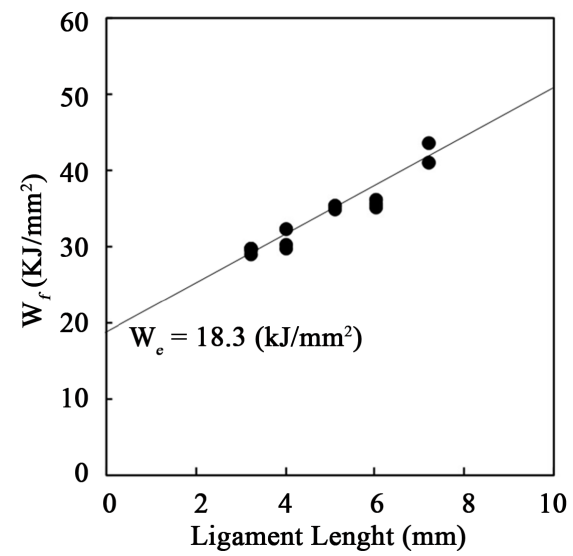

(d)

Figure 3. The results of fracture toughness obtained by EWF tests: (a) LN; (b) LM; (c) HM; (d) HW.

\subsection{Tensile Property Distribution}

Figure 4 shows the stress-strain curve obtained by tensile test. In this graph, every sample showed the own stress-strain curve distribution from the surface to core layer on each $50 \mu \mathrm{m}$. From this graph, every sample showed remarkably the different stress-strain curve as compared with that of the surface layer. Figure 5 and Figure 6 show the distribution of modulus and yield stress from the surface to core layer in each sample measured by Figure 4. In Figure 5, the high molecular weight sample showed higher modulus distribution than the low molecular weight samples in every layer. In HM and HW, the modulus distribution near surface showed a characteristic behavior. HW showed the highest modulus in $25 \mu \mathrm{m}$ depth from the surface, and then the modulus was decreased about $1.5 \mathrm{GPa}$ from $75 \mu \mathrm{m}$ depth to core layer. In contrast, the modulus of HM indicated the high value from 25 to $125 \mu \mathrm{m}$ depth, and then the value was decreased about $1.5 \mathrm{GPa}$ from $175 \mu \mathrm{m}$ to core layer. In LN and LM, these moduli showed a similar tendency with the case of HM and HW. Namely, the modulus of LM showed highest value at $25 \mu \mathrm{m}$ depth, and the modulus of LN indicated the high value from 25 to $125 \mu \mathrm{m}$ depth. It is considered that the difference could be due to the effect of molecular weight and molecular distribution of polypropylene. As shown in Figure 6, the results of the yield stress distribution showed a similar behavior with the results of modulus distribution.

From these results, the higher molecular weight and narrower molecular weight distribution sample showed higher modulus, yield stress and fracture toughness as compared with the other samples and these highly property samples had the highly property layer near the surface. Especially, this relationship can be observed at bulk yield stress and yield stress distribution. The high molecular weight and middle molecular weight distribution sample (HM) showed highest yield stress and modulus. In the modulus and yield stress distribution, it was found 


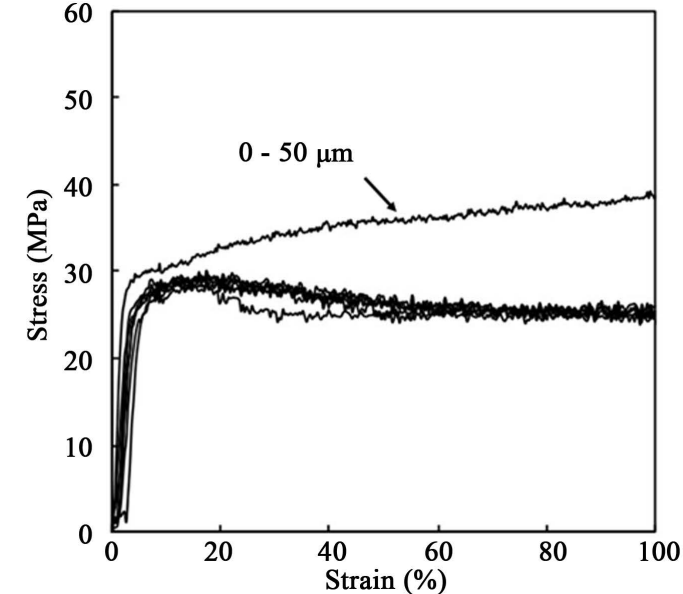

(a)

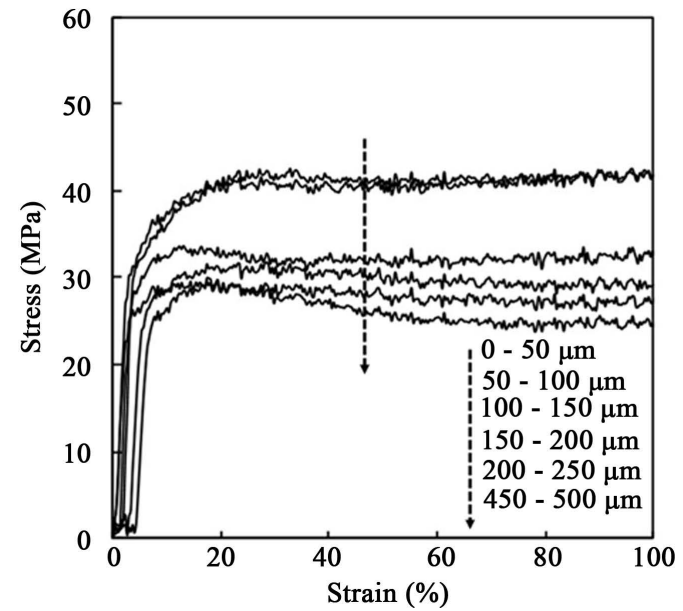

(c)

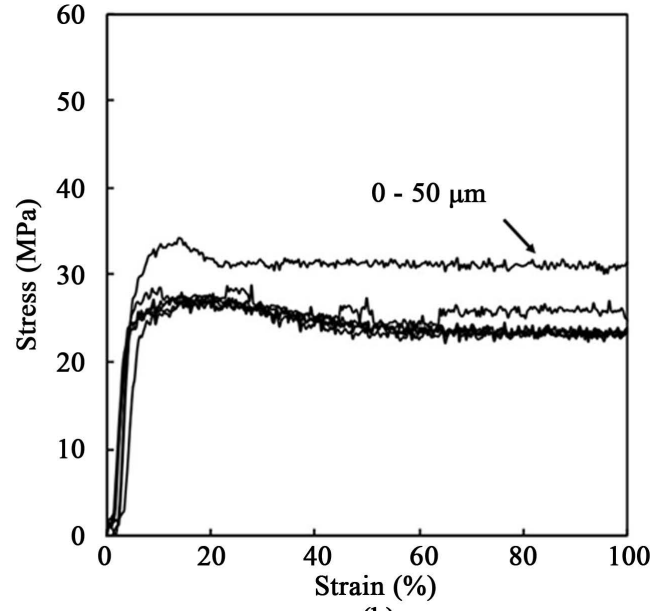

(b)

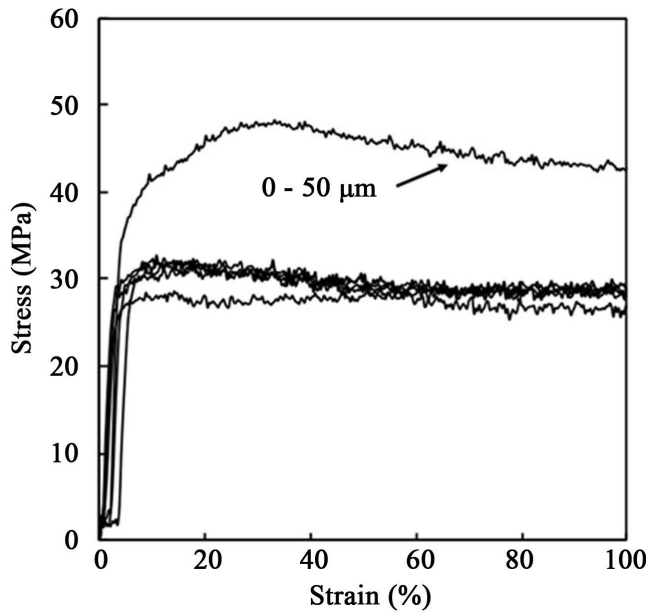

(d)

Figure 4. The stress-strain curve distributions from the surface to core layer on each sample enlarged at initial part: (a) LN; (b) LM; (c) HM; (d) HW.

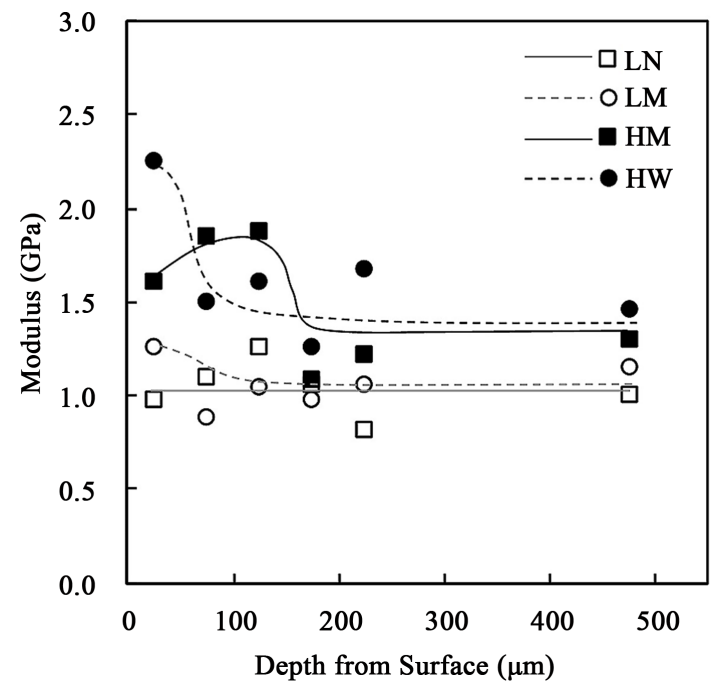

Figure 5. The modulus distribution from the surface to core layer on each sample, $\square$ : LN; ०: LM; $\mathbf{m : ~ H M ; ~ \bullet : ~}$ HW. 


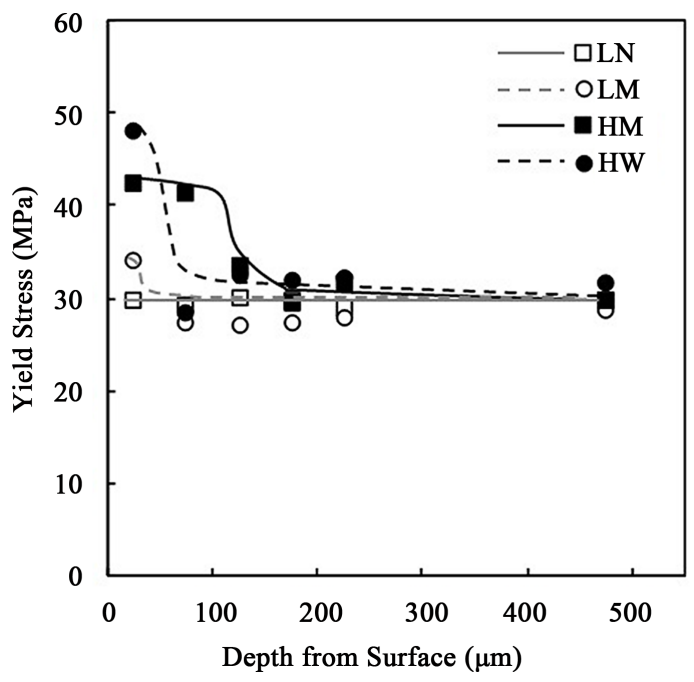

Figure 6. The yield stress distribution from the surface to core layer on each sample, ๑: LN; ०: LM; п: HM; •: HW.

that the HM sample had a thicker layer with high values near the surface as compared with the high molecular weight and wide molecular weight distribution sample (HW). In addition, it was found that the difference of distribution between HM and HW were not observed in the low molecular weight samples (LN and LM). In near future, the relationship between the molecular orientation, crystallinity, and mechanical properties of thin-walled PP molding parts will be investigated using X-ray deflection analysis and mechanical test.

\section{Conclusion}

In this research, the relationship between bulk mechanical property and mechanical property distribution of thin-wall injection molded polypropylene with different molecular weight and molecular weight distribution was investigated. The bulk mechanical properties were characterized in terms of static tensile property and fracture toughness by essential work of fracture method. The mechanical property distribution was measured by tensile test with thin-sliced dumbbell film obtained from bulk specimen. As results, it was found that the higher molecular weight and narrower molecular weight distribution sample indicated the higher modulus, yield stress, and fracture toughness as compared with the other samples. In addition, these samples had the highly property layer near the surface, it was considered that there is a correlation between these mechanical properties and the skincore structure. The property distribution test results revealed that the highly bulk property sample had thicker highly mechanical property layer on its surface. Therefore, the value of mechanical property layer in the surface rather than the thickness of highly mechanical property layer in the surface affect the increasing bulk mechanical property.

\section{References}

[1] Kantz, M.R., Newman, H.D. and Stigale, F.H. (1972) The Skin-Core Morphology and Structure-Property Relationships in Injection-Molded Polypropylene. Journal of Applied Polymer Science, 16, 1249-1260. http://dx.doi.org/10.1002/app.1972.070160516

[2] Fujiyama, M. and Wakino, T. (1991) Structures and Properties of Injection Moldings of Crystallization NucleatorAdded Polypropylenes. I. Structure-Property Relationships. Journal of Applied Polymer Science, 42, 2739-2747. http://dx.doi.org/10.1002/app.1991.070421012

[3] Clark, E. S. and Spruiell, J. E. (1976) Unlimited Flex Life in the Molded-In Hinge in Polypropylene: A Structural Hypothesis. Polymer Engineering \& Science, 16, 176-181. http://dx.doi.org/10.1002/pen.760160310

[4] Ito, H., Yagisawa, Y., Saito, T., Yasuhara, T. and Kikutani, T. (2005) Fundamental Study on Structure Development of Thin-Wall Injection Molded Products. Theoretical and Applied Mechanics Japan, 54, 263-268.

[5] Martin, J., Margueron, S., Hontana, M., Cochez, M. and Bourson, P. (2009) Study of the Molecular Orientation Heterogeneity in Polypropylene Injection-Molded Parts by Raman Spectroscopy. Polymer Engineering \& Science, 50, 
138-143. http://dx.doi.org/10.1002/pen.21524

[6] Zhu, P. and Graham, E. (2004) Morphological Distribution of Injection-Moulded Isotactic Polypropylene: A Study of Synchrotron Small Angle X-Ray Scattering. Polymer, 45, 2603-2613. http://dx.doi.org/10.1016/j.polymer.2004.02.031

[7] Jiang, K., Yu, F., Su, R., Yang, J., Zhou, T., Gao, J., Deng, H., Wang, K., Zhang, Q., Chen, F. and Fu, Q. (2011) High Speed Injection Molding of High Density Polyethylene-Effects of Injection Speed on Structure and Properties. Chinese Journal of Polymer Science, 29, 456-464. http://dx.doi.org/10.1007/s10118-011-1049-3

[8] Drummer, D. and Meister, S. (2014) Correlation of Processing, Inner Structure, and Part Properties of Injection Moulded Thin-Wall Parts on Example of Polyamide 66. International Journal of Polymer Science, 2014, 1-8. http://dx.doi.org/10.1155/2014/718926

[9] Yu, F., Deng, H., Zhang, Q., Wang, K., Zhang, C., Chen, F. and Fu, Q. (2013) Anisotropic Multilayer Conductive Networks in Carbon Nanotubes Filled Polyethylene/Polypropylene Blends Obtained through High Speed Thin Wall Injection Molding. Polymer, 54, 6425-6436. http://dx.doi.org/10.1016/j.polymer.2013.09.047

[10] Trotignon, J. and Verdu, J. (1987) Skin-Core Structure-Fatigue Behavior Relationships for Injection-Molded Parts of Polypropylene. I. Influence of Molecular Weight and Injection Conditions on the Morphology. Journal of Applied Polymer Science, 34, 1-18. http://dx.doi.org/10.1002/app.1987.070340101

[11] Fujiyama, M., Kitajima, Y. and Inata, H. (2002) Structure and Properties of Injection-Molded Polypropylenes with Different Molecular Weight Distribution and tacticity Characteristics. Journal of Applied Polymer Science, 84, 2142-2156. http://dx.doi.org/10.1002/app.10372

[12] Yokomizo, K., Banno, Y., Yoshikawa, T. and Kotaki, M. (2013) Effect of Molecular Weight and Molecular Weight Distribution on Weld-Line Interface in Injection-Molded Polypropylene. Polymer Engineering \& Science, 53, 23362344. http://dx.doi.org/10.1002/pen.23487

[13] Pistor, C. and Friedrich, K. (1997) Scratch and Indentation Tests on Polyoxymethylene (POM). Journal of Applied Polymer Science, 66, 1985-1996. http://dx.doi.org/10.1002/(SICI)1097-4628(19971205)66:10<1985::AID-APP15>3.0.CO;2-U

[14] Kody, R. and Martin, D. (1996) Quantitative Characterization of Surface Deformation in Polymer Composites Using Digital Image Analysis. Polymer Engineering \& Science, 36, 298-304. http://dx.doi.org/10.1002/pen.10416

[15] Dasari, A., Rohrmann, J. and Misra, R.D.K. (2002) Micro- and Nanoscale Evaluation of Scratch Damage in Poly(propylene)s. Macromolecular Materials and Engineering, 287, 889-903. http://dx.doi.org/10.1002/mame.200290024

[16] Chivatanasoontorn, V., Tsukise, S. and Kotaki, M. (2012) Surface Texture Effect on Scratch Behavior of Injection Molded Plastics. Polymer Engineering \& Science, 52, 1862-1867. http://dx.doi.org/10.1002/pen.23142

[17] Chivatanasoontorn, V., Yamada, K. and Kotaki, M. (2015) Highly Oriented Microstructures and Surface Mechanical Properties of Polypropylene (PP) Molded by Ultra-High Shear Rate. Polymer, 72, 104-112. http://dx.doi.org/10.1016/j.polymer.2015.07.013

[18] Mai, Y. and Cotterell, B. (1986) On the Essential Work of Ductile Fracture in Polymers. International Journal of Fracture, 32, 105-125. http://dx.doi.org/10.1007/BF00019787

[19] Kamide, K. and Fujii, K. (1967) Effects of Molecular Weight and Molecular Weight Distribution on Stretching Process of Polypropylene Filament (Part III). Necking Phenomena and Stretching Stress-Birefringence Relations. Sen'iGakkaishi, 23, 277-282. http://dx.doi.org/10.2115/fiber.23.277 